\title{
Multi-objective calibration of Xinanjiang model by using streamflow and evapotranspiration data
}

\author{
H.X. Li ${ }^{\mathrm{a}, \mathrm{b}}$, Y.Q. Zhang ${ }^{\mathrm{c}}$, G.H. Qin ${ }^{\mathrm{a}, \mathrm{b}}$ and L.R. Cao ${ }^{\mathrm{b}}$ \\ a State Key Laboratory of Hydraulics and Mountain River Engineering, Sichuan University, Chengdu, \\ 610065, China; \\ ${ }^{b}$ College of Water Resources \& Hydropower, Sichuan University, Chengdu, 610065, China; \\ ${ }^{c}$ CSIRO Land and Water, PO BOX 1700, Canberra ACT 2601, Australia \\ Email: yongqiang.zhang@,csiro.au
}

\begin{abstract}
Hydrological model calibration is normally carried out against a single set of observations, particularly streamflow, which often limit overall model performance. Compared to that, multi-objective model calibration can overcome these problems and result in better model performance. In this study, daily streamflow data and catchment evapotranspiration (ET) estimates in 210 catchments in southeastern Australia, were used for multi-objective calibration of Xinanjiang model. The daily ET was estimated from the state-of-the-art Penman-Monteith-Leuning (PML) model together with remotely sensed time-series vegetation data due to unavailability of actual ET data in most catchments. The results show that the PML ET estimates compare well with the flux measurements, and it is regarded as 'ground truth' and used for model calibration.

Two calibration schemes are used to evaluate hydrological modelling performance, including singleobjective calibration against streamflow data alone (Scheme 1) and multi-objective calibration against streamflow and evapotranspiration (Scheme 2). For model calibration, the median of NSE of daily streamflow for the 210 catchments are 0.78 and 0.76 for Scheme 1and Scheme 2, respectively, while the median of $\mathrm{R}^{2}$ between observed and simulated daily ET are 0.79 and 0.88 . Model regionalization results are overall consistent with the calibration results, with Scheme 2 showing a less degradation for streamflow and ET predictions compared to Scheme 1. The medians of NSE for Scheme 1 and Scheme 2 are 0.51and 0.52, respectively, while the median of $\mathrm{R}^{2}$ are 0.68 and 0.79 . The results show that the multi-objective calibration reduced the uncertainty of parameters and can improve runoff predictions in ungauged catchments. More researches should be carried out for further reducing the parameter uncertainty.
\end{abstract}

Keywords: Penman-Monteith, evapotranspiration, multi-objective calibration, runoff prediction 


\section{INTRODUCTION}

Parameters of hydrological models, in general, cannot be obtained directly from measurable quantities of catchment characteristics, and hence model calibration is needed (Madsen, 2000), which is a process of changing parameter values until a satisfactory agreement between simulated and observed catchment behavior is obtained. The hydrological model parameters are normally obtained from model calibration that is carried out either manually or by using computer-based automatic procedures. In last two to three decades, lots of researches have been devoted to develop automated calibration procedures based on numerical optimization techniques, such as the shuffled complex evolution (SCE) algorithm (Duan et al., 1992).

The automatic calibration procedures have focused mainly on using a single objective function to measure the goodness-of-fit of the calibrated model. Calibration based on a single performance measure, however, has some limitations (Efstratiadis and Koutsoyiannis, 2010) since it fits certain characteristics of the system response while neglecting others. These suggest the need of constraining the calibration processes by a larger number of objective functions, by the use of a multi-objective calibration (Engelandet al., 2006; Fenicia et al., 2007; Khu \& Madsen 2005; MacCabe et al., 2005; Zhang et al., 2016).

A multi-objective model calibration can be based on following three cases: (1) multi-variable observations(Efstratiadis and Koutsoyiannis, 2010), e.g. groundwater levels, river runoff, soil moisture, snow cover, etc;(2) multi-site observations (Engelandet al., 2006), i.e. the same variable observed at several sites within the catchment;(3) multi-response modes(Madsen, 2000), i.e. the use of objective functions that measure the fit of various response modes for the same variable, e.g. peak flows and low flows for the streamflow.Most of the multi-objective studies have focused on multi-response calibration (Madsen, 2000), but few studies use the multi-variable calibration.

The aim of this paper is to demonstrate feasibility of estimating model parameters using multi-variable observations. To this end, we use streamflow and evapotranspiration data for the multi-variable model calibration. Since catchment evapotranspiration data in most catchments are not available, we first use the state-of-the-art Penman-Monteith-Leuning (PML)model (Leuning et al, 2008 and Zhang et al, 2008)to estimate the catchment evapotranspiration time series and take it as 'ground truth' evapotranspiration, and then used the estimated evapotranspiration and streamflow for multi-objective calibration for a widely used hydrological model: the Xinanjiang model. Finally, the regionalization was carried out to evaluate the multiobjective model calibration scheme performance.

\section{MODEL AND DATA}

\subsection{Xinanjiang model}

The Xinanjiang model has been widely applied in humid and semi-humid regions in the world since its development in the 1970s (Zhao, 1992). It consists of three submodels: a three-layer evapotranspiration submodel, a runoff generation submodel, and a runoff routing submodel. The input data are daily precipitation (P) and pan evapotranspiration (EM), and the output is runoff/discharge (Q). The model has 14 parameters (Figure 1) and the physical meaning of the model parameters are given in Table 1.

\subsection{Study area and data}

There are 210 relatively unimpaired catchments $\left(50\right.$ to $\left.2000 \mathrm{~km}^{2}\right)$ in south-east Australia which includes the Murray-Darling Basin and the South-East Coast drainage basins that cover the most populated and important agricultural regions of Australia used in this study (Figure 2). Most catchments are in semi-humid and semiarid regions, with mean annual precipitation ranging from 406 to $1758 \mathrm{~mm}$, mean annual runoff from 4 to $902 \mathrm{~mm}$, and runoff coefficient from 0.1 to 0.7 .

In the PML evapotranspiration model, the meteorological time series (maximum temperature, minimum temperature, incoming solar radiation, actual vapour pressure), albedo, land cover data and daily time series of the leaf area index (LAI) are needed.

All the remotely sensed and meteorological data are reprojected, and clipped to the research area boundary. The gridded data in each catchment are then averaged to obtain aggregate daily data series for model inputs. 

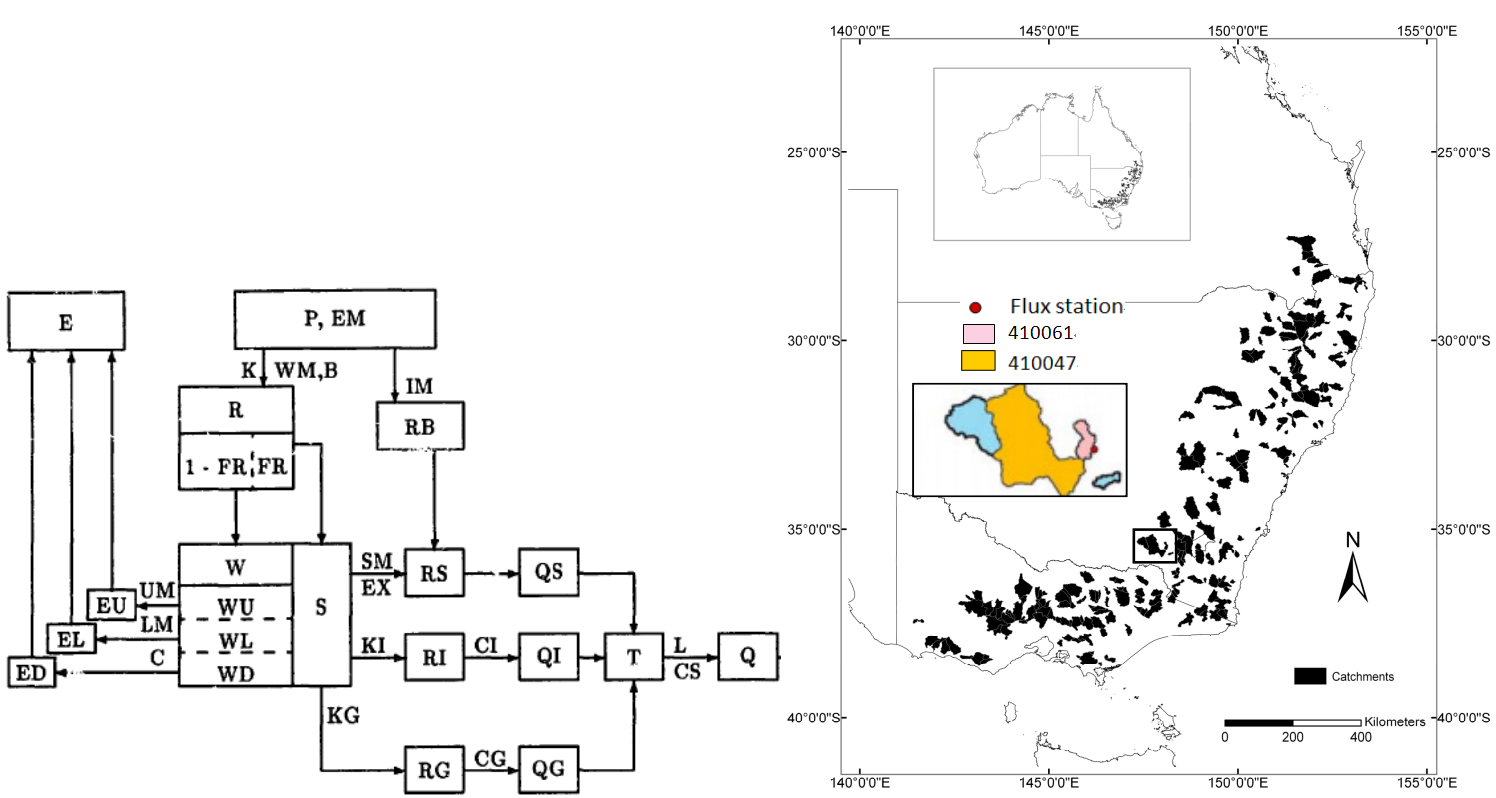

Figure 1. Structure of Xinanjiang model according to Zhao (1992). Figure 2. Locations of 210 catchments.

Table 1. Parameters of Xinanjiang model

\begin{tabular}{|c|l|}
\hline Parameter & Physical meaning \\
\hline UM & Averaged soil moisture storage capacity of the upper layer \\
\hline LM & Averaged soil moisture storage capacity of the lower layer \\
\hline DM & Averaged soil moisture storage capacity of the deep layer \\
\hline B & $\begin{array}{l}\text { Representation of the non-uniformity of the spatial distribution of the soil } \\
\text { moisture storage capacity over the catchment }\end{array}$ \\
\hline IM & Percentage of impervious and saturated areas in the catchment \\
\hline C & $\begin{array}{l}\text { Coefficient of the deep layer, that depends on the proportion of the basin } \\
\text { area covered by vegetation with deep roots }\end{array}$ \\
\hline SM & $\begin{array}{l}\text { Areal mean free water capacity of the surface soil layer, which represents } \\
\text { the maximum possible deficit of free water storage }\end{array}$ \\
\hline EX & $\begin{array}{l}\text { Exponent of the free water capacity curve influencing the development of } \\
\text { the saturated area }\end{array}$ \\
\hline KG & $\begin{array}{l}\text { Outflow coefficients of the free water storage to groundwater } \\
\text { relationships }\end{array}$ \\
\hline KI & Outflow coefficients of the free water storage to interflow relationships \\
\hline CG & Recession constants of the groundwater storage \\
\hline CI & \begin{tabular}{l} 
Recession constants of the lower interflow storage \\
\hline CS
\end{tabular} $\begin{array}{l}\text { Recession constant in the lag and route method for routing through the } \\
\text { channel system within each sub-basin }\end{array}$ \\
\hline L & Lag in time \\
\hline
\end{tabular}

\section{METHODS}

\subsection{PML evapotranspiration model}

The Penman-Monteith equation can be written as:

$$
E T=\frac{1}{\lambda} \frac{\Delta A+\rho_{a} C_{p} D G_{a}}{\Delta+\gamma\left(1+G_{a} / G_{s}\right)}
$$

where $E T$ is evapotranspiration, $\lambda$ is the latent heat of vaporization, $\Delta=d e^{*} / d T_{a}$, is the slope of the curve relating saturation water vapour pressure to temperature, $D=e^{*}\left(T_{\mathrm{a}}\right)-e_{\mathrm{a}}$ is the vapour pressure deficit of the 
air, $e^{*}\left(T_{a}\right)$ is the saturation vapour pressure at a given air temperature, $\mathrm{e}_{a}$ is the actual vapour pressure, $\gamma$ is the psychrometric constant, $\rho_{\mathrm{a}}$ is the air density, $C_{\mathrm{p}}$ is the specific heat capacity of air, $A$ is the available energy, the difference of the net radiation to the soil heat flux, $G_{a}$ is the aerodynamic conductance and $G_{s}$ is the surface conductance.

Except for the surface conductance, all the other variables can be calculated from meteorological time series data. Daily time series of LAI and meteorological data are required for calculation of $G_{s}$ (Eqs. (2) and (3)).

In PML evapotranspiration model, the surface conductance is estimated using the algebraic, biophysical sixparameter surface conductance model (Leuning et al., 2008):

$$
\begin{aligned}
& G_{s}=G_{c}\left[\frac{1+\frac{\tau G_{a}}{(1+\varepsilon) G_{c}}\left[f-\frac{(\varepsilon+1)(1-f) G_{c}}{G_{a}}\right]+\frac{G_{a}}{\varepsilon G_{i}}}{1-\tau\left[f-\frac{(\varepsilon+1)(1-f) G_{c}}{G_{a}}\right]+\frac{G_{a}}{\varepsilon G_{i}}}\right] \\
& G_{c}=\frac{g_{s x}}{k_{Q}} \ln \left[\frac{Q_{h}+Q_{50}}{Q_{h} \exp \left(-k_{Q} \mathrm{LAI}\right)+Q_{50}}\right]\left[\frac{1}{1+\frac{D}{D_{50}}}\right]
\end{aligned}
$$

where $\varepsilon$ is $\Delta / \gamma, G_{\mathrm{i}}=\gamma(A) /\left(\rho_{\mathrm{a}} C_{\mathrm{p}} D\right)$ is the isothermal conductance (Monteith and Unsworth, 1990), $G_{\mathrm{c}}$ is canopy conductance, $\tau=\exp \left(-k_{\mathrm{A}} \mathrm{LAI}\right)$ is the fraction of available energy transmitted downward at LAI, $g_{s x}$ is the maximum stomatal conductance, $k_{Q}$ is the extinction coefficient for photosynthetically active radiation, $k_{A}$ is the attenuation of net all-wave irradiance, $Q_{h}$ is the photosynthetically active radiation at the top of canopy, $Q_{50}$ is the value of absorbed photosynthetic active radiation when stomatal conductance $g_{s}=g_{s x} / 2\left(g_{s x}\right.$ is the maximum value of $\left.\mathrm{g}_{\mathrm{s}}\right), D_{50}$ is the value of $D$ when the stomatal conductance is reduced to $g_{\mathrm{sx}} / 2$, and $f$ is the fraction of equilibrium evapotranspiration at soil surface (varying between 0 to 1 ).

Estimation of the parameters is introduced in details by Zhang et al. (2008) and Leuning et al. (2008).

\subsection{Multi-objective calibration}

In the multi-objective calibration, optimization problem can be stated as follows (Madsen 2000):

$$
F(\theta)=\min \left\{F_{1}(\theta), F_{2}(\theta), \cdots, F_{p}(\theta)\right\} \theta \in \Theta
$$

where $\theta$ is the set of model parameters, $F_{1}(\theta), F_{2}(\theta), \cdots, F_{p}(\theta)$ are the different objective functions for $p$ number of objectives, and $\Theta$ is the feasible parameter space. It is well known that for calibration problems, the solution of equation (4) will not be a single unique solution with a corresponding single set of parameters. The solutions to a multi-objective problem will consist of the sets of solutions with trade-offs between the different objective functions. For each element in this solution set, known as Pareto optimal set, none of the objective functions can be further improved without a degradation of some of the other objective functions (hence forming the trade-off).

In the light of the Pareto-based approach, all Pareto optimal solutions are equally important, as it is difficult to prefer one solution over another without any further information about the problem. This does not mean, however, that an operational hydrologist who is interested in model simulations that fulfill the selected calibration objectives would regard all Pareto-optimal solutions as equally good. So the multi-objective calibration problem is usually transformed into a single-objective optimisation problem by defining a scalar that aggregates the various objective functions.

\subsection{Calibration schemes}

In this study, we simultaneously minimize two-objective functions, corresponding to streamflow and estimated evapotranspiration 


$$
\begin{aligned}
& F_{1}=1-N S E=\frac{\sum_{i=1}^{N}\left(Q_{o b s, i}-Q_{s i m, i}\right)^{2}}{\sum_{i=1}^{N}\left(Q_{o b s, i}-\overline{Q_{o b s}}\right)^{2}} \\
& F_{2}=1-R^{2}=1-\left(\frac{\sum_{j=1}^{M}\left(E T_{\text {sim }, j}-\overline{E T_{\text {sim }}}\right)\left(E T_{P M L, j}-\overline{E T_{P M L}}\right)}{\sqrt{\sum_{j=1}^{N}\left(E T_{\text {sim }, j}-\overline{E_{\text {sim }}}\right)^{2} \sum_{j=1}^{M}\left(E T_{P M L, j}-\overline{E T_{P M L}}\right)^{2}}}\right)^{2}
\end{aligned}
$$

where $Q_{\text {sim }}$ and $Q_{o b s}$ are the modelled and observed daily runoff respectively, $\overline{Q_{o b s}}$ is the arithmetic mean of the observed runoff, $E T_{\text {sim }}$ and $E T_{P M L}$ are the modelled and estimated daily evapotranspiration respectively, $\overline{E T_{s i m}}$ and $\overline{E T_{P M L}}$ is the arithmetic mean of $E T_{\text {sim }}$ and $E T_{P M L}, \quad i$ is the $i^{\text {th }}$ sample, $M$ and $N$ is the number of samples. The NSE is Nash-Sutcliffe Efficiency of daily streamflow; the $\mathrm{R}^{2}$ is the correlation coefficientbetween the simulated daily ET and PMLET estimates. It is noted that we use $\mathrm{R}^{2}$ of ET since we believe that PMLET time series data are more reliable (see Figure 3).

Two calibration schemes are used to compare the multi-objective calibration with single-objective calibration. Scheme 1 is single-objective calibration using Equation (5) as objective; Scheme 2 is multi-objective calibration using the aggregated objective based on two objectives as described above (Equation (5) and (6)). The aggregated objective of Scheme 2 is

$$
F=F_{1}+F_{2}
$$

Model performance is evaluated by calibration and regionalization because it is vital that the regionalization results are consistent with the calibration results, to ensure that the proposed method is reliable. For regionalization, each catchment is treated as 'ungauged' catchment and validated using parameters from the similar catchments. The spatial proximity method is used in this study for regionalization where the entire set of parameter values from the nearest catchment is used to model runoff in the 'ungauged' catchment.

\section{RESULTS}

\subsection{Estimation of evapotranspiration}

To evaluate the estimated evapotranspiration, the mean 10-day ET measured data (1/1/2002-12/31/2003) at the Tumbarumba flux tower $\left(E T_{o b s}\right)$ are compared with the mean 10-daycatchment-aggregated $E T_{P M L}$ at two nearby catchments (Figure 2). These are the closest of the 210 catchments to the flux station, which is located near the eastern boundary of catchment 410061 and to the northeast of catchment 410047 . Figure 3 shows that seasonal trends in 10-day $E T_{P M L}$ in both catchments are consistent with $E T_{o b s}$, but the peak values of $E T_{P M L}$ were less than those of $E T_{o b s}$ in summer.
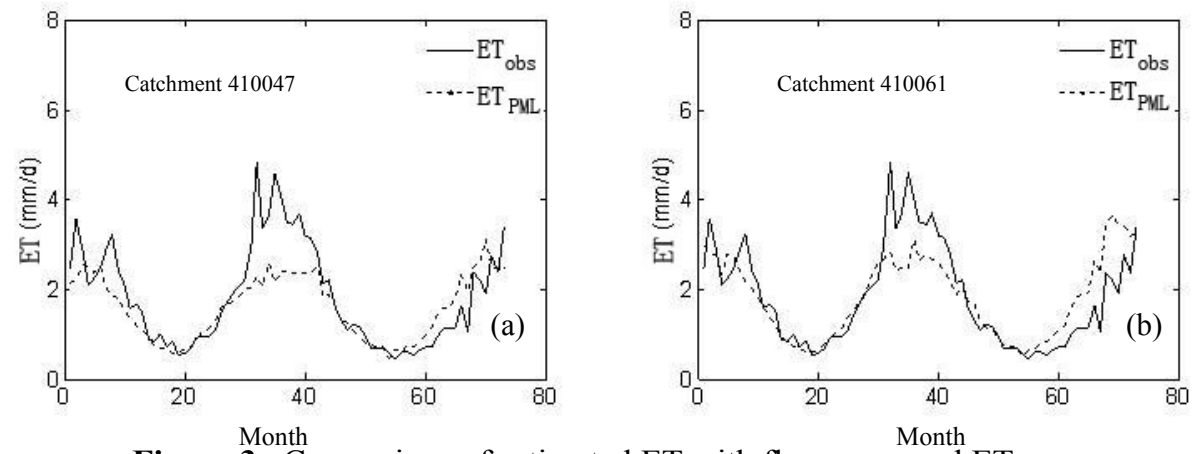

Figure 3. Comparison of estimated ET with flux-measured ET.

The generally good agreement between $E T_{P M L}$ and $E T_{o b s}$ is because the meteorology at the flux station is similar to that of catchments 410047 and 410061 . The reason why $E T_{o b s}$ is higher than $E T_{P M L}$ is that the flux station is surrounded by temperate broad-leaved forests, whereas the percent of woody area in catchment 410047 and 410061 is only $30 \%$ and $38 \%$, respectively. The rest of the catchments are covered by 
herbaceous vegetation that would be expected to have a lower evapotranspiration rate that the deeper-rooted, broad-leaved evergreen forest and so it is reasonable that peak $E T_{o b s}$ rates are higher than $E T_{P M L}$ in two catchments.

The results show that the PMLET estimates compare well with the flux-measured data, which means that the estimated ET can be regarded as 'ground truth' and used for model calibration.

\subsection{Multi-objective calibration}

The Multi-Objective Shuffled Complex Evolution Metropolis Algorithm (MOSCEM-UA) (Vrugt et al., 2003) is used in this study. Within a single optimization run, this algorithm generates a Pareto set of parameter combinations that best fit the data according to multiple objective functions. The estimated Pareto front for the calibration of streamflow and evapotranspiration of one catchment is shown in Figure 4.

The MOSCEM-UA results clearly illustrate that

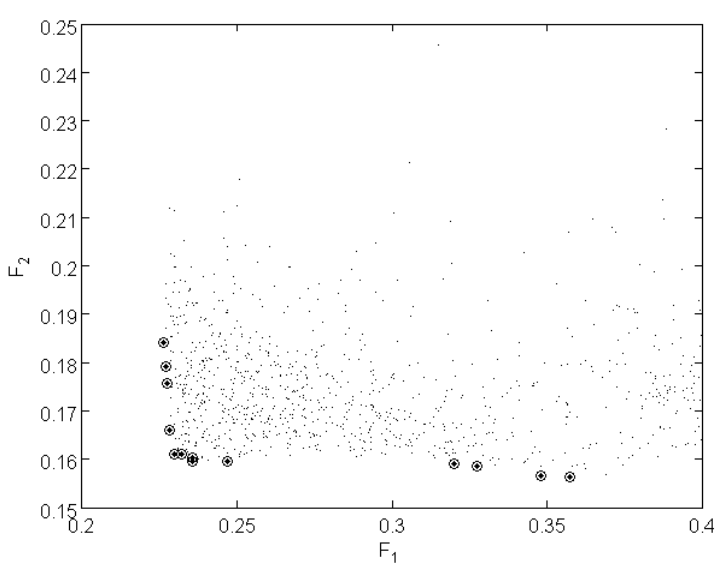

Figure 4. Pareto front and the correlation between objective functions. trade-offs occur between the two objectives, i.e. a very good calibration of streamflow provides a bad calibration of evapotranspiration, and vice versa. It means that optimization of each objective function separately, results in different optimized parameter sets and no single parameter set is able to simultaneously optimize all individual objectives. Similar results can be got when the multi-objective calibration is applied to the other catchments.

The calibration andregionalization results of the two schemes are summarized as cumulative distribution curves in Figure 5.Figure 5(a) and Figure 5(b) are calibration results of NSE and $\mathrm{R}^{2}$ betweenScheme1 (singleobjective) and Scheme2 (multi-objective), and Figure 5(c) and Figure 5(d) are regionalization results.
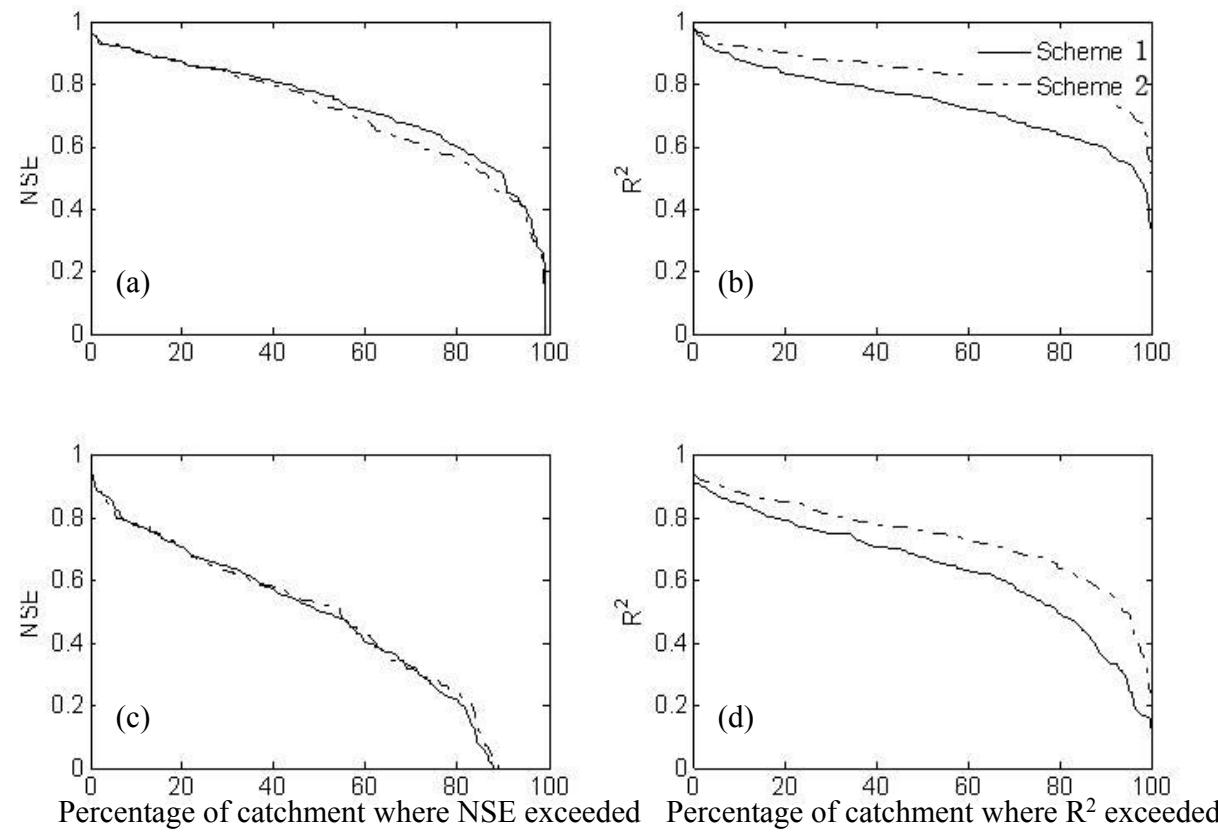

Figure 5. Calibration (a-b) and regionalization(c-d) results of two schemes.

Table 2. Calibration and regionalization results of two schemes (50\% quantile of NSE and $\left.\mathrm{R}^{2}\right)$

\begin{tabular}{|c|c|c|c|c|}
\hline \multirow{2}{*}{ Scheme } & \multicolumn{2}{|c|}{ NSE } & \multicolumn{2}{c|}{$\mathrm{R}^{2}$} \\
\cline { 2 - 5 } & Calibration & Regionalization & Calibration & Regionalization \\
\hline Scheme 1 & 0.78 & 0.51 & 0.79 & 0.68 \\
\hline Scheme 2 & 0.76 & 0.52 & 0.88 & 0.79 \\
\hline
\end{tabular}


For calibration, the median of NSE of the 210 catchments are 0.78 and 0.76 for Scheme 1 and Scheme 2, while the median of $\mathrm{R}^{2}$ are 0.79 and 0.88 , respectively (Table 2 ). For regionalization, results are consistent with the calibration results, and Scheme 2 has a more significant improvement than Scheme 1 . The median of NSE are 0.51 and 0.52 , while the median of $\mathrm{R}^{2}$ are 0.68 and 0.79 , respectively (Table 2 ). The results show that the multi-objective calibration reduced the uncertainty of parameters and can improve predictions in ungauged catchments.

\section{CONCLUSIONS}

In this study, daily streamflow data and catchment evapotranspiration estimates from PML model were used for multiple-objective calibration for Xinanjiang model. The results show that the PML model can provide a good estimation of catchment evapotranspiration. The multi-objective calibration against ET estimates and streamflow shows that significant trade-offs between two objectives are observed and no single unique set of parameter values is able to optimize all objectives simultaneously. Results show that the performance of multi-objective scheme is better than single-objective scheme, especially for regionalization. Our results indicate that multi-objective calibration can reduce the parameter uncertainty and improves runoff predictions in ungauged catchments. More researches should be carried out for further reducing the parameter uncertainty.

\section{ACKNOWLEDGMENTS}

This study was supported by the National Key Research \& Development(R\&D) Plan (No. 2016YFC0401903) and National Natural Science Foundation of China (No. 51209152).

\section{REFERENCES}

Duan, Q. Y., Sorooshian S., and Gupta V. (1992). Effective and efficientglobal optimization for conceptual rainfall-runoff models, Water Resources Research, 28(4), 1015-1031.

Efstratiadis, A. and Koutsoyiannis, D. (2010). One decade of multi-objective calibration approaches in hydrological modelling: a review. Hydrological Sciences Journal, 55(1), 58-78.

Engeland, K., Braud, I., Gottschalk, L. and Leblois, E., (2006). Multi-objective regional modelling. Journal of Hydrology, 327(3-4): 339-351.

Fenicia, F., Savenije, H. H. G., Matgen, P. and Pfister, L. (2007). A comparison of alternative multiobjective calibration strategies for hydrological modeling.Water Resources Research, 43, W03434, doi:10.1029/2006WR005098.

Khu, S. T. and Madsen, H. (2005). Multiobjective calibration with Pareto preference ordering: An application to rainfall-runoff model calibration.Water Resources Research, 41, W03004, doi:03010.01029/02004WR003041.

Leuning R., Zhang Y. Q., Rajaud A.and Cleugh H. A. (2008). A simple surface conductance model to estimate evaporation using MODIS leaf area index and the Penman-Monteith equation. Water Resources Research, doi:10.1029/2007WR006562.

Madsen, H. (2000). Automatic calibration of a conceptual rainfall-runoff model using multiple objectives. Journal of Hydrology, 235(3-4), 276-288.

McCabe, M.F., Franks, S.W. and Kalma, J.D. (2005). Calibration of a land surface model using multiple data sets. Journal of Hydrology, 302(1-4): 209-222

Vrugt, J. A., Gupta, H. V., Bastidas, L. A., Bouten, W.and Sorooshian, S. (2003b). Effective and efficient algorithm for multiobjective optimization of hydrologic models.Water Resources Research, 39, 1214, doi:1210.1029/2002WR001746.

Zhang R., Moreira M., Corte-Real J.(2016).Multi-objective calibration of the physically based, spatially distributed SHETRAN hydrological model. Journal of Hydroinformatics, 18 (3), jh2015219.

Zhang Y. Q, Chiew F. H. S., Zhang L., Leuning R.and Cleugh H. A. (2008). Estimating catchment evaporation and runoff using MODIS leaf area index and the Penman-Monetieth Equation. Water Resources Research, doi:10.1029/2007WR006563.

Zhao, R.J. (1992). The Xinanjiang Model Applied in China. Journal of Hydrology, 135(1-4): 371-381. 